\title{
Polycyclic aromatic hydrocarbons bioaccessibility in seafood: Culinary practices effects on dietary exposure
}

\author{
Fabíola Helena dos Santos Fogaça ${ }^{\mathrm{a}, \mathrm{b}}{ }^{*}$, Cristina Soares ${ }^{\mathrm{c}}$, Marta Oliveira ${ }^{\mathrm{c}}$, Ricardo N. Alves ${ }^{\mathrm{b}}$, \\ Ana L. Maulvault ${ }^{\mathrm{b}, \mathrm{d}, \mathrm{e}}$, Vera L. Barbosa ${ }^{\mathrm{b}}$, Patrícia Anacleto ${ }^{\mathrm{b}, \mathrm{d}, \mathrm{e}}$, João Avelar Magalhães ${ }^{\mathrm{a}}$, \\ Narcisa M. Bandarra ${ }^{\mathrm{b}}$, Maria João Ramalhosa ${ }^{\mathrm{c}}$, Simone Morais ${ }^{\mathrm{c}}$, António Marques ${ }^{\mathrm{b}, \mathrm{d}}$ \\ ${ }^{a}$ Embrapa Meio-Norte, Parnaíba, Brazil \\ ${ }^{\mathrm{b}}$ Division of Aquaculture and Upgrading (DivAV), Portuguese Institute for the Sea and Atmosphere (IPMA, I.P.), Lisbon, Portugal \\ ${ }^{c}$ REQUIMTE/LAQV, Instituto Superior de Engenharia do Porto, Porto, Portugal \\ d Interdisciplinary Centre of Marine and Environmental Research (CIIMAR), University of Porto, Porto, Portugal \\ ${ }^{\mathrm{e}}$ MARE - Marine and Environmental Sciences Centre, Faculty of Sciences, University of Lisbon (FCUL), Lisbon, Portugal
}

\section{A B S T R A C T}

\begin{abstract}
This work aimed to determine the effect of culinary practices on the contamination level and bioaccessibility of polycyclic aromatic hydrocarbons (PAHs) in seafood. The selected farmed seafood species (marine shrimp, clams and seaweed) were commercially available in Portugal. The mean concentrations of PAHs varied between 0.23 and $51.8 \mu \mathrm{g} \mathrm{kg}^{-1}$, with the lowest value being observed in raw shrimp and the highest in dried seaweed. The number of compounds detected in seaweed and clams (naphthalene, acenaphthene, fluorene, phenanthrene, benzo(b)fluoranthene and benzo(j)fluoranthene) were higher than in shrimp (fluorene and pyrene). Among the PAHs measured, fluorene was the predominant one. There was a significant interaction effect between species and culinary treatment $(p<0.05)$, thus boiled and dried seaweed samples presented the lowest and the highest levels of fluorene $\left(0.13\right.$ and $\left.1.8 \mu \mathrm{gg}^{-1}\right)$, respectively. The daily intake of PAHs decreased with bioaccessibility, varying from $22 \%$ for benzo(k)fluoranthene (in raw clam) to $84 \%$ for phenanthrene (in steamed clam). According to the potency equivalent concentrations, screening values and bioaccessibility of PAHs, the consumption of marine shrimp, clam and seaweed is considered as safe for consumers.
\end{abstract}

\author{
Keywords: \\ Polycyclic aromatic hydrocarbons \\ Seafood \\ Bioaccessibility \\ Daily intake \\ In vitro digestion
}

\section{Introduction}

Seafood is an important source of proteins, healthy lipids, vitamins and minerals in the Portuguese's diet, which recorded the highest annual consumption rate in the EU $52.2 \mathrm{~kg}$ by person year ${ }^{-1}$ (Food and Agriculture Organization, 2016). However, some seafood can accumulate organic lipophilic nonpolar pollutants such as polycyclic aromatic hydrocarbons (PAHs), from the aquatic environment (Nasher et al., 2016), representing a potential risk for consumers.

PAHs are ubiquitous and persistent compounds with two or more benzene rings fused in various arrangements (Yu et al., 2012), that are formed during pyrolysis or incomplete combustion of organic material (Veiga et al., 2014). Man-made sources of PAHs include motor-vehicle exhausts, emissions from industry, commercial and household heating with coal, wood or other biomass fuels, indoors tobacco smoke (Li et al., 2014) and cooking processes (Singh et al., 2016). The pyrolysis of organic matter, such as fat, carbohydrate and protein, at temperatures above $200^{\circ} \mathrm{C}$ promotes $\mathrm{PAH}$ formation, as well as the yield of lipids dripping in direct contact over the flame at intense heat (Hamidi et al., 2016).

These compounds are organic lipophilic, non-biodegradable, environmentally persistent, toxic and categorized as carcinogen (Ledesma et al., 2014). Because of their toxicity, mutagenic and/or carcinogenic properties, the US Environmental Protection Agency listed 16 PAHs as priority compounds (EPA, 2005). Benzo(a)pyrene is the only known carcinogen (group 1; IARC, 2010) whereas naphthalene, benz(a)anthracene, benzo(b)fluoranthene, benzo(j)fluoranthene, benzo(k)fluoranthene, chrysene, and indeno(1,2,3-cd)pyrene are considered as possible carcinogens to humans (group 2B; IARC, 2002, 2010); dibenzo(a,l) pyrene and dibenz(a,h)anthracene are considered probable carcinogens to humans (group 2A; IARC, 2010). They are easily and rapidly absorbed by organisms, passing into the marine food chain (Martinez et al., 2004), and consequently promoting seafood contamination.

The human exposure to PAHs occurs mainly through ingestion

\footnotetext{
* Corresponding author at: Division of Aquaculture, Embrapa Meio-Norte, Parnaíba, Piauí, Brazil.

E-mail addresses: fabiolafogaca@yahoo.com.br, fabiola.fogaca@embrapa.br (F.H. dos Santos Fogaça).
} 
(88-98\%), followed by inhalation (2-12\%) (Alomirah et al., 2011). Oral bioaccessibility testing has been adopted for measuring contaminants fraction released from the food matrices that can be absorbed by the human gastrointestinal tract after ingestion and digestion (Koch et al., 2013).

Bioaccessibility tests can be carried out using in vitro models, which are simple, easy, cost-effective, provide accurate results in a short time and reduce the need of animal experimentation (Hamidi et al., 2016). Despite already validated for PAHs, only few studies employed this tool to assess these compounds bioaccessibility in seafood and its relationship with culinary practices (Dosunmu et al., 2016; Soriano et al., 2007; Wang et al., 2010; Yu et al., 2012). The bioaccessibility of PAHs from Shanghai seafood were determined in shrimp, clam, carp and croaker with shrimp presenting the lowest levels of PAHs and clam the highest levels and, revealing $47.2 \%$ of bioaccessibility on average (Yu et al., 2012). Shrimps can bioaccumulate contaminants from water and sediment (Dosunmu et al., 2016), while filter feeding organisms like bivalves can absorb contaminants from water and plankton (Soriano et al., 2007). Thus, these species can be used as sentinel organisms for monitoring PAHs in the environment and may, simultaneously, be an important tool to assess human exposure to contaminants (Mercogliano et al., 2016).

In order to gather more data on contamination of PAHs in seafood and to characterize the effects of different culinary practices on dietary exposure of this contaminant group, PAHs bioaccessibility was determined in several seafood species (shrimp, clams and seaweed) from different geographic origins (Equator, Vietnam and Portugal).

\section{Material and methods}

\subsection{Reagents and materials}

The reference mixture of PAHs (EPA 610) (naphthalene, acenaphthylene, acenaphthene, fluorene, phenanthrene anthracene, fluoranthene, pyrene, benz(a)anthracene, chrysene, benzo(b)fluoranthene, benzo(k)fluoranthene, ben-zo(a)pyrene, dibenz(a,h)anthracene, benzo(g,h,i)perylene and indeno(1,2,3-cd)pyrene) and individual standards of each compound, benzo(j)fluoranthene and dibenzo(a,l) pyrene were purchased from Supelco (Bellefonte, PA, USA). Mixed standard solutions containing all PAHs were prepared by dilution of the stock solutions with acetonitrile and stored at $-20^{\circ} \mathrm{C}$ in the darkness to avoid volatilization and photodegradation. Acetonitrile was purchased from Sigma-Aldrich (Steinheim, Germany) and ultrapure water was obtained from a Milli-Q simplicity 185 system (Millipore, Bedford, MA, USA).

\subsection{Sample collection, cooking and proximate chemical composition}

Samples of marine shrimp (Litopenaeus vannamei; $\mathrm{n}=270,3.0 \mathrm{~kg}$ ) and clams (Meretrix lyrata; $\mathrm{n}=240,3.3 \mathrm{~kg}$ ) originated from Equator and Vietnam aquaculture farms were purchased from Portuguese markets in Lisbon. A total of $5.0 \mathrm{~kg}$ of marine seaweed (Ulva sp.) were caught in aquaculture ponds situated in Olhão city, Algarve region, South of Portugal. All samples were transported to the laboratory in clean polyethylene bags according to the recommendations of EFSA (2008) and processed immediately upon arrival.

Raw shrimp specimens were carefully cleaned, headed and peeled; clams were washed and if necessary opened. Only the edible tissues of shrimps and clams were preserved; a sample for analysis consisted of a minimum mass of $200 \mathrm{~g}$. A portion of each fresh sample (raw) was kept without any cooking treatment. Each treatment was prepared, in duplicate, with 30 shrimps and 40 clams each. Different portions of shrimp and clam samples were steamed at $105^{\circ} \mathrm{C}$ during 5 and $7 \mathrm{~min}$, respectively. Shrimp fillets were prepared and spiced over $15 \mathrm{~min}$ with salt $(1.5 \% \mathrm{w} / \mathrm{w})$ and garlic cloves $(1 \% \mathrm{w} / \mathrm{w})$ and fried in extra virgin olive oil ( $2 \% \mathrm{w} / \mathrm{v}$ after removing garlic from the fillets) during $5 \mathrm{~min}$ at $180^{\circ} \mathrm{C}$. Portions of fresh seaweed samples were boiled in distilled water $(1: 20 \mathrm{w} / \mathrm{v})$ during $15 \mathrm{~min}$, drained, cooled and, when reached room temperature, weighed in order to define the uptake of water during boiling (Maehre et al., 2016). Dried seaweed samples were prepared by drying portions of the fresh samples during $48 \mathrm{~h}$ at $50^{\circ} \mathrm{C}$. Both raw and cooked samples were homogenized with a blender $(800 \times \mathrm{g}, 10 \mathrm{~min})$ and stored at $-20^{\circ} \mathrm{C}$ until further analysis.

Moisture was evaluated according to the Portuguese Standard NP 2282-1991 and the official AOAC method (AOAC, 2007). Total ash content was assessed through the complete combustion of samples over $16 \mathrm{~h}$ at $500{ }^{\circ} \mathrm{C}$, until a constant weight was achieved (AOAC, 2005). Crude protein and fat contents were determined according to the methodologies described by Saint-Denis and Goupy (2004) and Folch et al. (1957), respectively.

\subsection{Bioaccessibility assays}

Bioaccessibility was assessed using a static in vitro human digestion protocol adapted from Versantvoort et al. (2005), being calculated according to the following equation:

Bio $(\%)=\left([\mathrm{PAHs}]_{\text {bio }} \times 100\right) /[\mathrm{PAHs}]_{\text {fresh sample }}$

where Bio (\%) is the bioaccessibility of a specific compound, $[\mathrm{PAH}]_{\mathrm{bio}}$ is the concentration of the PAH on the bioaccessible fraction, and $[\mathrm{PAHs}]_{\text {fresh sample }}$ is the concentration of the compound in the fresh sample (adapted from Manita et al., 2017).

The simulated gastro-intestinal (GI) digestion was performed in three consecutive phases: saliva, gastric and intestinal by using saliva $(\mathrm{pH} 7.0)$, gastric juice $(\mathrm{pH} 2.0)$, duodenal juice and bile $(\mathrm{pH} 7.0)$ digestion fluids, respectively. Briefly, $1.5 \mathrm{~g}$ of shrimp (raw, fried, and steamed) and clam (raw and steamed) samples was stirred during $5 \mathrm{~min}$ with $4.0 \mathrm{ml}$ of artificial saliva. Then, $8.0 \mathrm{ml}$ of artificial gastric juice and 2 drops of pure hydrochloric acid (A.C.S., 37\%, Sigma-Aldrich, Saint Louis, USA) were added, followed by $2 \mathrm{~h}$ of incubation at $37^{\circ} \mathrm{C}$ with constant rotation. Additionally $8 \mathrm{ml}$ of artificial duodenal juice, $4 \mathrm{ml}$ of artificial bile and $1.3 \mathrm{ml}$ of sodium bicarbonate (A.C.S., $\geq 99.7 \%$, Sigma-Aldrich, Saint Louis, USA) were added to the extract and submitted to a second incubation $\left(2 \mathrm{~h}\right.$ at $37^{\circ} \mathrm{C}$ ). Digestion was stopped by immersion of samples on ice during $5 \mathrm{~min}$. The digested and non-digested fractions of samples were separated through centrifugation at $2750 \times g\left(4^{\circ} \mathrm{C}, 10 \mathrm{~min}\right)$. The simulated GI digestion for seaweed was performed according to Maehre et al. (2016), namely reducing the enzymes (amylase, pepsin, and pancreatin) by $50 \%$ due to the lower protein content $(2-3 \%)$ in algae samples. Approximately $1 \mathrm{~g}$ of boiled and $0.5 \mathrm{~g}$ of raw and dried seaweed samples was used.

To confirm the in vitro digestion efficiency, total protein levels were determined in shrimp, clam, and seaweed raw and cooked samples before digestion and in the non-bioaccessible (NBIO) fractions by-using a combustion method of analysis with the FP-528 DSP LECO nitrogen analyser (LECO, St. Joseph, MI, USA) calibrated with EDTA according to the Dumas method (Saint-Denis and Goupy, 2004).

\subsection{Extraction and chromatographic analysis of PAHs}

Microwave-assisted extractions were performed in a MARS-X $1500 \mathrm{~W}$ (Microwave Accelerated Reaction System for Extraction and Digestion, CEM, Mathews, NC, USA) and according to the validated conditions previously described by Ramalhosa et al. (2012a, 2012b). Briefly, $1 \mathrm{~g}$ of fresh and $0.5 \mathrm{~g}$ for lyophilized samples were extracted with $10 \mathrm{ml}$ of acetonitrile at $110^{\circ} \mathrm{C}$ during 20 min with a medium stirring speed. The solvent selection (acetonitrile), its volume, the extraction temperature and time were previously optimized and validated by Ramalhosa et al. (2012b), with quantitative extraction rates over $70 \%$ for all PAHs. After cooling, extracts were completely dried using a rotary evaporator (Buchi Rotavapor, R-200) at $20^{\circ} \mathrm{C}$, being the residue re-dissolved in $250 \mu \mathrm{L}$ of acetonitrile. 
To quantify PAHs, extracts were analysed according to previous works of the team (Ramalhosa et al., 2012a, 2012b) by high-performance liquid chromatography (Shimadzu Corporation, Kyoto, Japan) with photodiode array (PAD) and on line fluorescence (FLD) detectors. The methodology used for the analysis of PAHs was validated through systematic recovery experiments $(70.2 \pm 4.8 \%$ for benzo(g,h,i)perylene to $101.2 \pm 4.2 \%$ for pyrene) and with the analysis of certified reference material SRM 2977: Mussel tissue (Ramalhosa et al., 2012b). Limits of detection (LODs) and quantification (LOQs) were calculated as the minimum detectable amount of analyte with a signal-to-noise ratio of 3:1 and 10:1 (Miller and Miller, 2000). The LOD ranged between $0.3 \mu \mathrm{g} \mathrm{L}^{-1}\left(0.08 \mu \mathrm{g} \mathrm{kg}^{-1} \mathrm{ww}\right)$ for dibenz(a,h)anthracene to $36.4 \mu \mathrm{g} \mathrm{L}^{-1}$ $\left(9.10 \mu \mathrm{gg}^{-1} \mathrm{ww}\right)$ for acenaphthylene (Table $1 \mathrm{~S}$ of the Supplementary material). Analytical blanks and PAHs standards were daily analysed to check instrument performance. Each analysis was performed at least in triplicate. Further details are presented in Section 1S of Supplementary material.

PAHs concentrations were determined in wet (ww) and dry (dw) weight basis, however to simplify the discussion of results only the concentrations in ww are presented.

\subsection{Dietary intake}

The dietary intake (DI) of PAHs through seafood consumption was calculated according to the following expression (Nasher et al., 2016).

$\mathrm{DI}=(\mathrm{C} \times \mathrm{m} \times \mathrm{IR}) / \mathrm{BW}$

Where $C$ is the average concentration of total PAHs $\left(\mu \mathrm{gg}^{-1}\right), \mathrm{m}$ is the food consumption rate: $150 \mathrm{~g} \mathrm{day}^{-1}$, ww for clam and shrimp (Nasher et al., 2016) and $5 \mathrm{~g} \mathrm{day}^{-1}$ for seaweed (Bouga and Combet, 2015), IR is the bioaccessibility (\%) and BW is the average body weight for the general population (60 kg for adults) (Nasher et al., 2016).

\subsection{Statistical analysis}

Data were expressed as mean and standard deviation. The normality test of Shapiro-Wilk ( $\alpha=5 \%$ ) was used. Samples with PAHs levels lower than the limit of quantification (LOQ) were not used for statistical analysis. Dependence of PAHs concentrations and fat content was examined using Pearson correlation coefficient. A general linear model (ANOVA and Tukey test) was used to determine significances differences $(p<0.05)$ between species. The culinary practices, species and their interaction effects were analysed by a completely randomized design, in a factorial scheme $3 \times 2$ (three species $\times$ culinary treatments, raw and cooked) with six replicates (Table 2S). All statistical procedures were computed using Statistica version 12.0 (StatSoft, Poland) and Assistat version 7.7 (Silva and Azevedo, 2016).

\section{Results}

\subsection{Proximate composition}

The proximate composition of raw and cooked samples (shrimp, clam and seaweed) is shown in Table 1. Cooking induced a moisture reduction in the shrimp and dried seaweed samples and an increase of ash content in shrimp, clam and dried seaweed $(\mathrm{p}<0.05)$. For dried seaweed, the moisture reduction of $80 \%$ corresponds to the water loss during drying. Crude protein and fat levels were higher in fried and steamed shrimp, as well as in dried seaweed (Table 1). No significant differences were found between raw and steamed clam samples $(p>0.05)$.

\subsection{PAH levels}

The concentrations of acenaphthylene, anthracene, fluoranthene, benz(a)anthracene, chrysene, benzo(a)pyrene, dibenzo(a,l)pyrene,
Table 1

Proximate composition (\%) of raw and cooked shrimp, clam and seaweed samples.

\begin{tabular}{lllll}
\hline $\begin{array}{l}\text { Proximate } \\
\text { composition } \\
\text { (\%) }\end{array}$ & Moisture & Ash & Crude protein & Crude fat \\
\hline Shrimp & & & & \\
Raw & $81.34 \pm 0.63^{\mathrm{a}}$ & $0.86 \pm 0.06^{\mathrm{b}}$ & $19.58 \pm 0.47^{\mathrm{b}}$ & $0.84 \pm 0.11^{\mathrm{b}}$ \\
Fried & $74.47 \pm 0.42^{\mathrm{b}}$ & $1.74 \pm 0.10^{\mathrm{a}}$ & $22.73 \pm 0.30^{\mathrm{a}}$ & $2.03 \pm 0.07^{\mathrm{a}}$ \\
Steamed & $74.99 \pm 0.48^{\mathrm{b}}$ & $1.49 \pm 0.05^{\mathrm{a}}$ & $24.61 \pm 0.60^{\mathrm{a}}$ & $1.50 \pm 0.05^{\mathrm{a}}$ \\
Clam & & & & \\
Raw & & & & \\
Steamed & $79.59 \pm 1.47^{\mathrm{a}}$ & $1.29 \pm 0.11^{\mathrm{a}}$ & $15.06 \pm 0.89^{\mathrm{a}}$ & $1.49 \pm 0.07^{\mathrm{a}}$ \\
Seaweed & & & & \\
Raw & $92.08 \pm 0.45^{\mathrm{a}}$ & $2.12 \pm 0.11^{\mathrm{b}}$ & $3.30 \pm 0.52^{\mathrm{b}}$ & $0.19 \pm 0.01^{\mathrm{b}}$ \\
Boiled & $92.01 \pm 0.31^{\mathrm{a}}$ & $1.38 \pm 0.05^{\mathrm{c}}$ & $2.21 \pm 0.04^{\mathrm{c}}$ & $0.19 \pm 0.01^{\mathrm{b}}$ \\
Dried & $11.78 \pm 0.15^{\mathrm{b}}$ & $25.47 \pm 0.43^{\mathrm{a}}$ & $15.24 \pm 0.38^{\mathrm{a}}$ & $0.96 \pm 0.07^{\mathrm{a}}$ \\
\hline
\end{tabular}

Different letters $(\mathrm{a}-\mathrm{c})$ correspond to statistically different means $(\mathrm{p}<0.05)$ within each group. $n=6$.

dibenz(a,h)anthracene, benzo(ghi)perylene, and indeno(1,2,3-cd)perylene in shrimp, clam, and seaweed samples (raw and cooked) were below their respective limits of detection and therefore were not considered for further analysis. The mean concentration of total PAHs ranged from 0.2 to $51.8 \mu \mathrm{g} \mathrm{kg}^{-1}$, with the lowest value being observed in raw shrimp and the highest in dried seaweed (Table 2). The contamination pattern in raw species was: clam $>>$ shrimp $\approx$ seaweed. In general, a higher number of compounds were detected in seaweed and clam [naphthalene, acenaphthene, fluorene, phenanthrene, benzo (b)fluoranthene + benzo(j)fluoranthene (as $\mathrm{B}(\mathrm{b}) \mathrm{Ft}+\mathrm{B}(\mathrm{j}) \mathrm{Ft}$ ) and benzo (k)fluoranthene) compared to shrimp (fluorene and pyrene) (Table 2).

The PAH contamination pattern after the culinary methods was the following: fried shrimp $>$ raw shrimp $\approx$ steamed shrimp; steamed clam $>$ raw clam; dried seaweed $>>$ boiled seaweed $>$ raw seaweed. For shrimp, steaming did not affect the concentration of fluorene, while frying reduced the levels of fluorene and triggered an increase of pyrene. For clams, steaming increased benzo(b)fluoranthene + benzo(j) fluoranthene and phenanthrene contents. Boiling of seaweed enabled the reduction of fluorene concentration. The drying treatment applied to seaweed mainly induced acenaphthene and phenanthrene accumulation, while boiling decreased naphthalene accumulation. Fluorene content was higher in dried seaweed, when compared to raw and boiled samples (Table 2).

The evaluation of interaction effects of culinary treatments and species was carried out for raw and steamed treatments, because they were common to all samples (Table 3 ). A significant effect $(\mathrm{p}<0.05$ ) was observed for the species and interaction between species and culinary treatment for fluorene. Steamed clams presented the highest levels of fluorene and the highest interaction effects between cooked treatments and the species, while boiled seaweed showed the lowest values (Table 3). Clams presented the highest levels of fluorene, while shrimp and seaweed showed statistically similar values (Table 4). The correlations between PAHs global mean concentrations and lipid contents are presented in Fig. 1. As shown, moderate to strong positive Pearson correlations (r) were found for raw shrimp $(0.7<\mathrm{r}<1$; $p<0.05$ ), steamed and fried shrimp and raw seaweed samples $(0.4<\mathrm{r}<0.6)$; boiled $(\mathrm{r}=0.2)$ and dried $(\mathrm{r}=0.3)$ seaweed samples as well as raw and steamed clams $(r=0.2)$ presented positive but weaker correlations between total PAH levels and crude fat content (Fig. 1).

\subsection{PAHs composition profiles and source identification}

Among shrimp, clam, and seaweed samples the most predominant PAHs were of those with low-molecular-weight (LMW - acenaphthene, phenanthrene, fluorene, pyrene, and naphthalene), being the high- 
Table 2

Concentrations of individual and total PAHs ( $\Sigma \mathrm{PAH}$, mean $\pm \mathrm{SD}$, range, $\mu \mathrm{g} \mathrm{kg}^{-1} \mathrm{ww}$ ) in raw and cooked samples.

\begin{tabular}{|c|c|c|c|c|c|c|c|c|c|}
\hline PAHs & Naph & Ace & Flu & Phe & Pyr & $B(b) F t+B(j) F t$ & $\mathrm{~B}(\mathrm{k}) \mathrm{Ft}$ & ІPAH & Range \\
\hline \multicolumn{10}{|l|}{ Shrimp } \\
\hline Raw & ND & ND & $0.23 \pm 0.05^{\mathrm{a}}$ & ND & ND & ND & ND & $0.23 \pm 0.05$ & $0.19-0.43$ \\
\hline Fried & ND & ND & $0.14 \pm 0.04^{\mathrm{b}}$ & ND & $0.60 \pm 0.10$ & ND & ND & $0.74 \pm 0.10$ & $0.14-0.81$ \\
\hline Steamed & ND & ND & $0.28 \pm 0.10^{\mathrm{a}}$ & ND & ND & ND & ND & $0.28 \pm 0.10$ & $0.19-0.39$ \\
\hline \multicolumn{10}{|l|}{ Clam } \\
\hline Raw & $1.38 \pm 0.48^{\mathrm{a}}$ & ND & $0.25 \pm 0.1^{\mathrm{a}}$ & $0.27 \pm 0.06^{\mathrm{b}}$ & ND & $2.04 \pm 0.17^{\mathrm{b}}$ & $0.15 \pm 0.03^{\mathrm{a}}$ & $4.08 \pm 0.70$ & $0.14-4.53$ \\
\hline Steamed & $1.60 \pm 0.85^{\mathrm{a}}$ & ND & $0.34 \pm 0.09^{\mathrm{a}}$ & $0.58 \pm 0.19^{\mathrm{a}}$ & ND & $2.28 \pm 0.11^{\mathrm{a}}$ & $0.17 \pm 0.02^{\mathrm{a}}$ & $4.97 \pm 0.77$ & $0.12-5.72$ \\
\hline \multicolumn{10}{|l|}{ Seaweed } \\
\hline Raw & ND & ND & $0.27 \pm 0.07^{\mathrm{b}}$ & ND & ND & ND & ND & $0.27 \pm 0.07$ & $0.20-0.34$ \\
\hline Boiled & $0.96 \pm 0.29$ & ND & $0.13 \pm 0.06^{\mathrm{b}}$ & ND & ND & ND & ND & $1.09 \pm 0.35$ & $0.16-1.52$ \\
\hline Dried & ND & $49.11 \pm 5.19$ & $1.78 \pm 0.92^{\mathrm{a}}$ & $0.96 \pm 0.07$ & ND & ND & ND & $51.85 \pm 4.28$ & $0.72-52.9$ \\
\hline
\end{tabular}

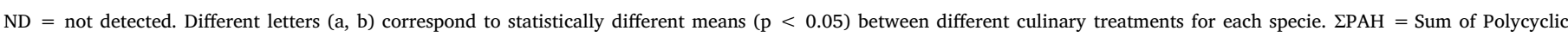

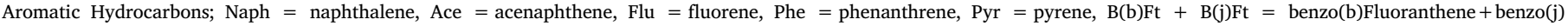
Fluoranthene, $\mathrm{B}(\mathrm{k}) \mathrm{Ft}=$ benzo(k)fluoranthene. $n=6$.

Table 3

Interaction effect of species and culinary treatment with the fluorene global mean concentrations ( $\left.\mu \mathrm{g} \mathrm{kg}^{-1} \mathrm{ww}\right)$ in raw and cooked samples.

\begin{tabular}{lll}
\hline \multicolumn{2}{l}{ Fluorene concentrations $\left(\mu \mathrm{kg}^{-1}\right.$ ww) } & \\
\hline Samples & Raw & Steamed/Boiled \\
\hline Shrimp & $0.23^{\mathrm{aA}}$ & $0.28^{\mathrm{bA}}$ \\
Clam & $0.25^{\mathrm{aB}}$ & $0.34^{\mathrm{aA}}$ \\
Seaweed & $0.27^{\mathrm{aA}}$ & $0.13^{\mathrm{bB}}$ \\
C.V. (\%) & 26.8 & \\
\hline
\end{tabular}

Values are presented as average and C.V. represents the coefficient of variation. Means in the same column with different letters are significantly different $(p<0.05)$. Uppercase letters present differences in interactions between culinary treatments and species, and lowercase differences between species. $n=6$.

Table 4

Effect of species (raw) on the fluorene global media concentrations ( $\mu \mathrm{g} \mathrm{kg}^{-1} \mathrm{ww}$ ).

\begin{tabular}{lll}
\hline Species & Flu & C.V. (\%) \\
\hline Shrimp & $0.25^{\mathrm{b}}$ & 17 \\
Clam & $0.29^{\mathrm{a}}$ & 24 \\
Seaweed & $0.17^{\mathrm{b}}$ & 58 \\
\hline
\end{tabular}

Values are presented as average and C.V. represents the standard deviation. Means in the same column with different letters are significantly different $(\mathrm{p}<0.05)$ between species. $n=6$.

molecular weight compounds (HMW - benzo(b)fluoranthene, benzo(j) fluoranthene, and benzo(k)fluoranthene) only detected in clam samples (Table 2). The LMW PAHs, such as naphthalene, acenaphthene and fluorene, were dominant, accounting approximately $100 \%$ of all PAHs in seaweed, and in raw and steamed shrimp (Fig. 2). The concentrations of fluorene in shrimp samples varied from $19 \%$ (fried) to $100 \%$ (raw and steamed), pyrene was only detected in fried shrimp samples and accounted for $81 \%$ of total PAHs (Fig. 2). In raw and steamed clam samples, benzo(b)fluoranthene and benzo(j)fluoranthene were the most abundant compounds (46-50\% of total PAHs), followed by naphthalene (33-34\%), phenanthrene (7-12\%), fluorene (6-7\%), and benzo(k) fluoranthene $(2-3 \%)$. Fluorene was the predominant compound in raw seaweed samples, however its contribution was strongly reduced after boiling (12\% of total PAHs) and drying (3\%). Naphthalene (88\%) and acenaphthene (95\%) were the compounds that contributed the most for total PAHs in boiled and dried seaweed samples, respectively (Fig. 2).

Regarding diagnostic ratios determination it was observed that mean LMW/HMW ratio was 0.9 for raw and 1.0 for steamed clam samples, suggesting the presence of combustion sources (Hornbuckle and Robertson, 2010). Values of naphthalene/phenanthrene ratios $>1$ were also indicative of the predominance of pyrogenic sources in clam samples (Ravindra et al., 2008).

\subsection{PAHs bioaccessibility}

The bioaccessibility of PAHs is presented in Fig. 3. Among the seven PAHs detected in the samples of shrimp, clams and seaweed, only benzo (k)fluoranthene was detected in the bioaccessible fraction of raw and steamed clams, fluorene in steamed clam and phenanthrene in dried seaweed (Fig. 3). The results showed that bioaccessibility of PAHs ranged from $22 \%$ to $58 \%$ for $\mathrm{B}(\mathrm{k}) \mathrm{Ft}$ (in raw and steamed clam, respectively), $84 \%$ for Phe (in steamed clam), and $60 \%$ for fluorene in dried seaweed. The steaming process increased $\mathrm{B}(\mathrm{k}) \mathrm{Ft}$ bioaccessibility from $22 \%$ to $58 \%$ in clam (Fig. 3).

\subsection{Estimation of human daily intake}

The calculated total daily intake (based on Nasher et al., 2016) of PAHs via seafood consumption was $0.3 \mu \mathrm{g}$ day $^{-1}$, in which PAHs intake from dried seaweed, raw and steamed clam and raw, steamed, and fried shrimp was $0.04,0.10,0.12,0.01,0.01$, and $0.02 \mu \mathrm{g} \mathrm{day}^{-1}$, respectively. When total PAH bioaccessibility was integrated into the estimation, the global PAHs DI significantly decreased to $0.15 \mu \mathrm{g} \mathrm{day}^{-1}$, promoting a reduction of $50 \%$ in the total intake of PAHs $\left(0.02 \mu \mathrm{g} \mathrm{day}^{-1}\right.$ for raw clam, $0.1 \mu \mathrm{g} \mathrm{day}^{-1}$ for steamed clam, $0.03 \mu \mathrm{g} \mathrm{day}^{-1}$ for dried seaweed and zero for the other samples since no compounds were detected in the bioaccessible fraction). Among the analysed samples, steamed clam played a very important role in PAHs ingestion, which accounted with $68.4 \%$ of the total DI, but when bioaccessibility was considered, dried seaweed played a more relevant contribution for total DI (81.7\%) (Fig. 4). This high contribution was attributed to the high bioaccessibility levels of PAHs presented in seaweed compared to both clam samples.

\section{Discussion}

The current study revealed that for shrimp heat induced protein denaturation and loss of water in steamed and fried treatments, and promoted pyrene accumulation in the fried samples. During frying, the high temperatures favor PAHs formation (in this study, mainly pyrene) and food contamination by aromatization and de-hydrocyclization of mono-unsaturated hydrocarbons present in oils and fats (Olatunji et al., 2014). Still, shrimp showed significantly lower total PAHs (इPAHs) when compared to previous studies concerning fried fish ( $\Sigma$ PAHs of $35.4 \mu \mathrm{g} \mathrm{kg}^{-1}$ Perelló et al., 2009). These variations depend of several factors: like species, size, type of oil, oil penetration, frying duration and temperature achieved (Olatunji et al., 2015).

The culinary effect was also observed for dried seaweed. Drying is a 


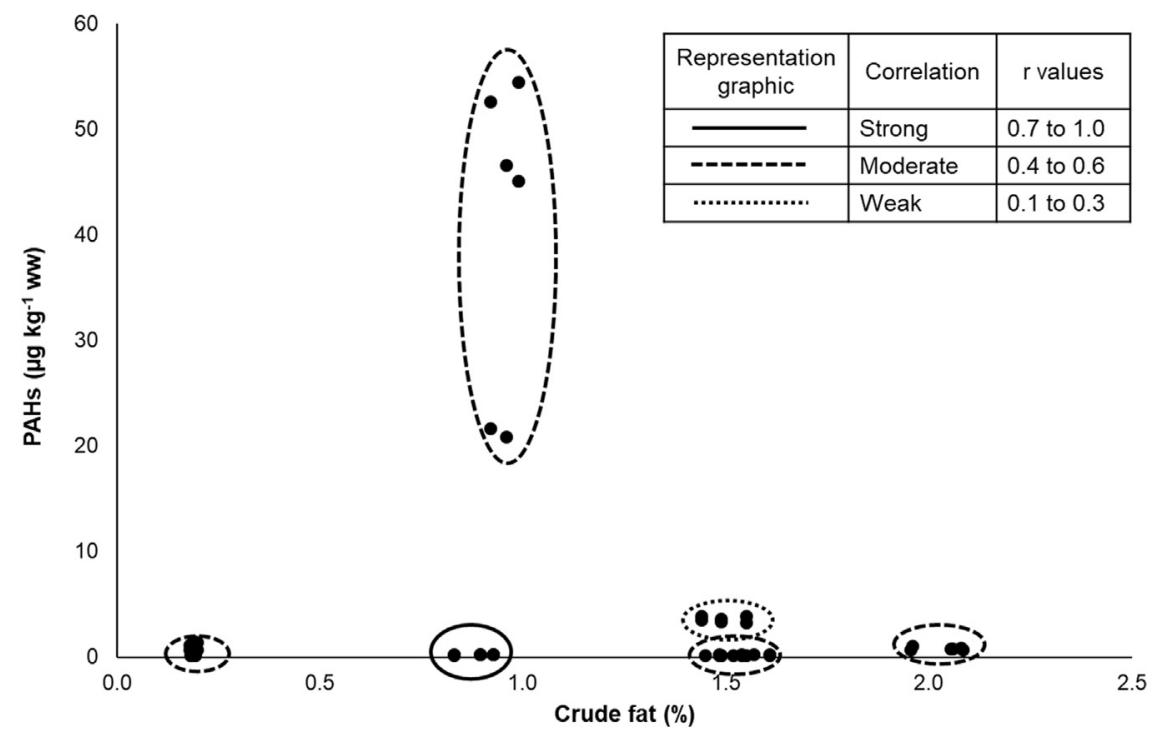

Fig. 1. Correlation between mean total PAHs concentration $\left(\mu \mathrm{kg}^{-1} \mathrm{ww}\right)$ and crude fat (\%) content in the samples.

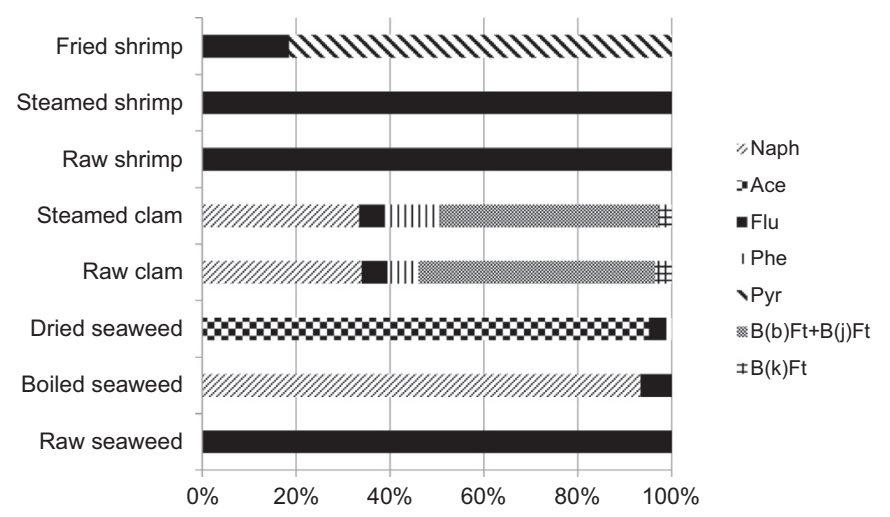

Fig. 2. PAHs composition profiles in the analysed samples. Naph $=$ naphthalene, Ace $=$ acenaphthene, Flu = fluorene, Phe = phenanthrene, Pyr = pyrene, $\mathrm{B}(\mathrm{b}) \mathrm{Ft}+\mathrm{B}(\mathrm{j}) \mathrm{Ft}$ $=$ benzo(b)fluoranthene + benzo(j)fluoranthene, $\mathrm{B}(\mathrm{k}) \mathrm{Ft}=$ benzo(k)fluoranthene $(n=6)$.

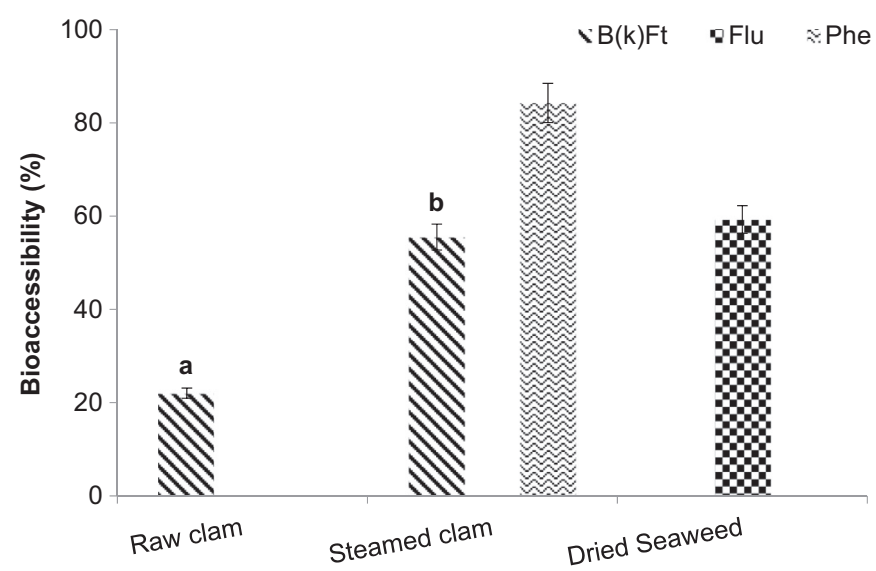

Fig. 3. PAHs bioaccessibility (\%) in raw and steamed clam and in dried seaweed samples. $\mathrm{Flu}=$ fluorene, $\mathrm{Phe}=$ phenanthrene, $\mathrm{B}(\mathrm{k}) \mathrm{Ft}=$ benzo(k)fluoranthene. $(\mathrm{a}, \mathrm{b})$ Correspond to statistically different means $(p<0.05)$.

commonly used method for moisture removal of food for better conservation (Singh et al., 2016). In this study, dried seaweed was made to simulate the nori processing for sushi, with the purpose of evaluating the Ulva sp. potential for culinary usage and the risk associated with its consumption. Dried seaweed showed higher levels of protein, ash and lipid when compared to the others seaweed treatments (Table 1). The same behavior was observed for PAHs concentration in seaweed, where: the dried treatment induced the highest PAH levels (Table 2). Despite the low temperature of the drying process $\left(50^{\circ} \mathrm{C}\right)$, the long duration $(48 \mathrm{~h})$ associated with the high nutrients concentration, can promoted the formation of higher levels of PAHs (López-Jiménez et al., 2014). Phenanthrene presence in dried seaweed has also been observed in roasted seed oil (sunflower), proving that roasting and drying can promote PAHs formation at low temperatures (Neđeral et al., 2014). Currently, there are no studies with data on bioaccessibility of PAHs in seaweed, thus seaweed results were compared with studies performed with mate herb. During the herb drying process, PAHs formation occurs, being detected even in tea infusions for consumption, with high levels of high-molecular-weight PAHs (Thea et al., 2016). In the present work, dried seaweed presented only lower-molecular-weight PAHs (Table 2), probably due to environmental contamination from petroleum products.

For clams, culinary treatments showed no effect $(p>0.05)$ in proximate composition between raw and steamed products (Table 1), but as far as PAHs concentrations are concerned (Table 2), an effect was observed of species and culinary treatment interaction on phenanthrene and benzo(b)fluoranthene + benzo(j)fluoranthene contents. Clams tend to present a balance between the uptake and depuration of PAHs, and can maintain a relatively constant tissue concentration (Guinan et al., 2001), specially for medium and low molecular weight PAHs like fluorene (Mercogliano et al., 2016).

The interaction effects of species and culinary treatments show that not only the heat process, but also the type of food matrix, as well as their origin, are important for PAHs bioaccumulation. Low molecular weight PAHs (LMW, 2-3 aromatic rings) are formed and/or released during crude oil maturation processes, and storage, transport, and use of crude oil products (petrogenic sources), while PAHs with high molecular weights (HMW, high number of aromatic rings) are frequently released during all kind of combustion processes (pyrogenic sources) (Abdel-Shafy and Mansour, 2016). In this study limited diagnostic ratios could be determined; still they suggested the predominance of pyrogenic sources in clam specimens. A higher number of samples would allow a better estimation of the PAH sources in both raw and cooked seafood samples. Moreover, the use of diagnostic ratios to differentiate among petrogenic and pyrogenic sources of PAHs is very complex mostly because the ratios among compounds change in different proportions and are strongly dependent on the environmental conditions. It should be noted that PAHs of petroleum origin are the 
a)

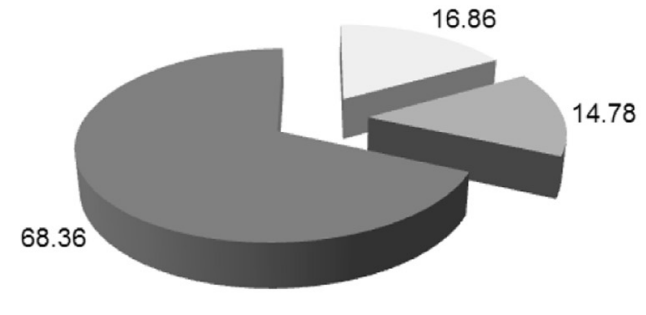

Dried seaweed $\quad$ Raw clam $\quad$ Steamed clam b)

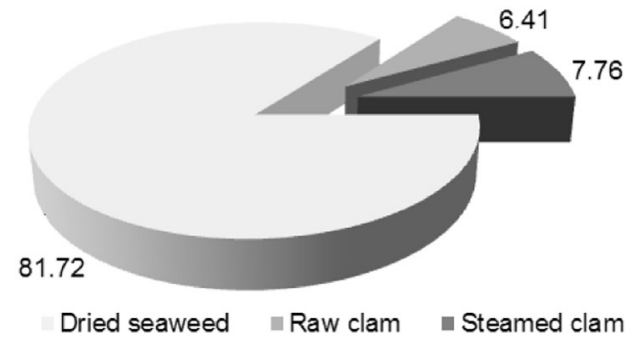

Fig. 4. Daily Intake (DI, \%) of PAHs in raw and steamed clam and in dried seaweed samples without (a) and with (b) bioaccessibility assays.

most frequently found in aquatic environments (Kettrup et al., 1999). Fish are able to metabolize PAHs, but they tend to bioaccumulate these compounds more intensely only when they live very close to a source of contamination. Also, crustaceans possess a well-developed detoxification cytochrome P-450 system whose enzyme activity increases in a dose-dependent level on the PAHs exposure (Ren et al., 2014). Bivalve mollusks do not have well-developed detoxification systems and can bioaccumulate medium and low molecular weight PAHs, even when present at low concentrations in the environment (Albers and Cairns, 2003). Besides that, low-molecular-weight PAHs with three or four rings are generally more prone to bioaccumulation than those with five or six rings in bivalve mollusks (Bordajandi et al., 2004; Palma-Fleming and Gutierrez, 2004). This was registered for shrimp and seaweed, whereas for clams, lower and higher molecular weight PAHs was found in samples (Table 2). PAHs produced by pyrolysis are emitted to the atmosphere during forest fires, fossil fuels and wood combustion, industrial process and cooking (Naccari et al., 2011). Pollutants can deposit on the water surface and the uptake by clams may occur directly from the dissolved phase, but also from suspended particles (high molecular PAHs are predominantly adsorbed/absorbed from particulate matter of air) (Oliveira et al., 2017).

The geographic origin of the species was also evaluated because the bioaccumulation of PAHs mainly depends on biota feeding preference and trophic level, as well environmental contamination (Hamidi et al., 2016). When comparing our results with previous studies, the shrimp (Macrobrachium felicinum) collected in Nigeria presented fluorene values of $7.0 \mu \mathrm{g} \mathrm{kg}^{-1}$ (Dosunmu et al., 2016) i.e. about 3500 times higher than those determined for the Equator shrimp acquired in Portugal $\left(0.2 \mu \mathrm{g} \mathrm{kg}^{-1}\right.$, Table 2). Mussels from Naples gulf, Italy, showed higher levels of pyrolytic PAHs due to the industrial activity registered in the surrounding area (Mercogliano et al., 2016), while the characterized mussels from Vietnam showed the same proportion of petrogenic and pyrogenic PAHs.

The lipid deposits, body structure and texture, metabolism, etc., also affect the bio-concentration and PAHs accumulating properties in marine organisms (Mostafa, 2002). Thus, because of their organic lipophilic properties, PAHs have greater affinity with animal tissues with more lipid content. In this study, for all samples, this aspect was not observed by Pearson correlation between crude fat and total PAHs concentrations (Fig. 1). As shown in Fig. 1, only raw shrimp showed a strong correlation $(r=0.7)$ compared with other samples. Clams had the highest concentrations of PAHs and the weaker correlations $(0.2<\mathrm{r}<0.3)$; seaweeds presented a moderate correlation for raw and boiled treatments, and a weak correlation for dried samples. According to Yu et al. (2012), crude lipid in seafood was not the most important factor influencing the accumulation of PAHs. For clams it is intrinsically related with the lower ability to metabolically transform PAHs to less toxic forms and to excrete them (Singh et al., 2016), thus being bioaccumulated in lipid tissues. As previously mentioned, clams do not have an efficient metabolism system for PAHs, and, apparently, seaweed shows this deficiency too. The bioconcentration and transformation of benz(a)pyrene by brown, red and green seaweed (as Ulva lactuca) was studied by Kirso and Irha (1998). These authors concluded that brown seaweeds do not biotransform B(a)P, but bioacumulate it, while red and green algae present the ability to metabolize PAHs in a proportion of $42-49 \%$ of total PAHs available through enzymatic activity.

Regarding PAHs profile (Fig. 2), no PAHs classified by US EPA and IARC as carcinogenic (possible/probable) were detected in shrimp and seaweed samples (cooked and uncooked); naphthalene, benzo(b)fluoranthene, benzo(j)fluoranthene, and benzo(k)fluoranthene, known possible carcinogens (group 2B; IARC, 2002, 2010) were detected in raw and steamed clam samples (Table 2; Fig. 2). European Comission Regulation (EC n. 835/2011) set maximum allowed levels of PAHs in seafood at $2.0 \mu \mathrm{g} \mathrm{kg}^{-1}$ for benzo(a)pyrene and $12.0 \mu \mathrm{g} \mathrm{kg}^{-1}$ for the sum of benzo(a)pyrene + benzo(a)anthracene + benzo(b)fluoranthene + chrysene (European Comission, 2011). Naphthalene, also a known possible carcinogen (IARC, 2002) and listed by the California State (USA) as a known cause of cancer $\left(0.1 \mathrm{mg} / \mathrm{kg} \mathrm{day}^{-1}\right)$ (OEHHA, 2005) was detected in clam and seaweed samples at low concentration levels (1.0-1.6 $\mu \mathrm{g} \mathrm{kg}^{-1}$ ) (Table 2). The profile of PAHs in seafood depends on the environmental conditions where marine organisms grow, on their metabolic activity and biometric characteristics (López-Jiménez et al., 2014). In previous studies, phenanthrene was the dominant compound $\left(115.8 \mu \mathrm{g} \mathrm{kg}^{-1}\right)$, accounting for majority of PAHs load for shrimp (Macrobrachium felicinum) from Nigeria (Dosunmu et al., 2016) and for farm mussels $\left(43.3 \mu \mathrm{g} \mathrm{kg}^{-1}\right.$ ) from Italy (Mercogliano et al., 2016). Yet, in this work, phenanthrene was not detected in shrimp samples (Table 2). In a study conducted with different food items (meat, tea, fish, etc.) in Shanghai, China, among all PAHs detected, 33.7\% corresponded to phenanthrene, followed by fluorene (17.9\%), with the exception for clam, which presented fluoranthene as the predominant congener. According to the authors, fluorene was the predominant PAH in marine shrimp samples (Yu et al., 2012). These results corroborate those obtained in the present study (Fig. 2).

The reduced number of PAHs and their low levels in samples was directly reflected in PAHs bioaccessibility. Indeed, fluorene presented $59.29 \%$ bioaccessibility in dried seaweed, benzo(k)fluoranthene presented $22.0 \%$ in raw clams and $55.5 \%$ in steamed clams, phenanthrene showed $84.2 \%$ in steamed clam (Fig. 3), and marine shrimp did not present bioaccessibility for any PAH due to the reduced PAH levels. However, in a previous study, the same shrimp species (from China) presented $30.8 \%$ of pyrene and $35.6 \%$ of fluorene bioaccessibility (Yu et al., 2012). Wang et al. (2010) reported that PAH bioaccessibility in fish from Hong Kong markets ranged from $12.6 \%$ to $42.6 \%$ using the same in vitro simulation. These values are approximately half of those determined in the present study (Fig. 3). Oral contaminants bioaccessibility is based on standardized methodologies established for studies of metal species in environmental solids (ISO, 2007). Despite no standard protocol has been defined yet for persistent organic pollutants (POPs) like PAHs in seafood (Rodríguez-Navas et al., 2017), the European REACH (Registration, Evaluation, Authorization and Restriction of Chemicals) ethical guidelines discourage the use of tests on experimental organisms (Schoeters, 2010) and recommends the use of in vitro 
methodologies. Therefore, PAHs bioaccessibility studies are extremely relevant necessary based on the premises that oral ingestion of contaminated seafood is often considered as the primary human exposure pathway to POP (Ortega-Calvo et al., 2015). Accordingly, estimation of PAHs human daily intake (PAHs DI) should integrate PAH bioaccessibility. Dried seaweed presented the highest PAH bioaccumulation (Table 2), thus contributing with $80 \%$ of PAHs DI. In addition, the cooking process did not influence PAHs DI for clams when bioaccessibility was integrated into the DI estimation (Fig. 4). However, the detected PAHs levels were very low and presented no health risks to consumers. Dosunmu et al. (2016) and Hong et al. (2016) described similar results. Dosunmu et al. (2016) assessed the risk of human exposure to PAHs via shrimp consumption and concluded that lifetime cancer risk was unlikely for inhabitants of coastal zones that are likely to consume high amounts of shrimp species. No risk was also observed for the consumption of oyster from Dalian, Northeast China (Hong et al., 2016). On the other hand, for Shanghai consumers, shellfish (snail and clam) played a very important role in PAHs DI and might put consumers at risk if their consumption pattern is high and over long periods due the high levels of PAHs (Yu et al., 2012).

\section{Conclusion}

Species and culinary treatments are two variables that need to be taken into account in exposure to PAHs through seafood consumption. This effect is more evident in clams. Bivalves have a greater ability to bioaccumulate PAHs than shrimp and seaweed. A significant positive relationship was observed between lipid content and PAH concentrations, suggesting the important role of lipids in the accumulation of PAHs in raw shrimp. Bioaccessibility decreased the potency equivalent PAH concentrations for clams and seaweed, which indicated that bioaccessibility should be taken into account for health risk assessment with regard to PAHs contamination in seafood. In this context, the inclusion of bioaccessibility and culinary processes in risk assessment provides more realistic estimates of PAHs human exposure through seafood consumption.

\section{Acknowledgments}

This work received financial support from European (FEDER funds through COMPETE) and Portuguese funds (Fundação para a Ciência e Tecnologia Project UID/QUI/50006/2013). The Portuguese Foundation for Science and Technology supported the Ph.D. Grant of ALM (SFRH/ BD/103569/2014) as well as the post-doc Grant of P.A. (SFRH/BPD/ 100728/2014) and the IF2014 contract of AM.

\section{References}

Abdel-Shafy, H.I., Mansour, M.S.M., 2016. A review of polycyclic aromatic hydrocarbons: source, environmental impact, effect on human health and remediation. Egypt. J. Pet. 25, 107-123.

Albers, P.H., 2003. Petroleum and individual polycyclic aromatic hydrocarbons. In: David, B.A.R., Hoffman, J., Allen Burton Jr.G., Cairns Jr.John (Eds.), Handbook of Ecotoxicology, 2nd ed. Lewis Publisher, Boca Raton, pp. 341-370.

Alomirah, H., et al., 2011. Concentrations and dietary exposure to polycyclic aromatic hydrocarbons (PAHs) from grilled and smoked foods. Food Control 22, 2028-2035.

AOAC, 2005. AOAC-Association of Official Analytical Chemists. Official Methods of Analysis of AOAC International, 18th ed. AOAC International, Gaithersburg, Maryland, USA

AOAC, 2007. Official Methods of Analysis of AOAC International, 18th ed. AOAC International, Arlington.

Bouga, M., Combet, E., 2015. Emergence of seaweed and seaweed-containing foods in the UK: focus on labeling, iodine content, toxicity and nutrition. Foods 4, 240-253.

Bordajandi, L.R., et al., 2004. Survey of persistent organochlorine contaminants (PCBs,
$\mathrm{PCDD} / \mathrm{Fs}$, and PAHs), heavy metals ( $\mathrm{Cu}, \mathrm{Cd}, \mathrm{Zn}, \mathrm{Pb}$, and $\mathrm{Hg}$ ), and arsenic in food samples from Huelva (Spain): levels and health implications. J. Agric. Food Chem. 52, 992-1001.

Dosunmu, M.I., et al., 2016. Risk assessment of human exposure to polycyclic aromatic hydrocarbons via shrimp (Macrobrachium felicinum) consumption along the Imo River catchments, SE Nigeria. Environ. Geochem. Health 38, 1333-1345.

European Comission, 2011. Commission Regulation (EU) No 835/2011 of 19 August 2011 amending Regulation (EC) No 1881/2006 as regards maximum levels for polycyclic aromatic hydrocarbons in foodstuffs. Off. J. Eur. Union - Legis. 215, 4-8.

EPA, 2005. Guidelines for Carcinogen Risk Assessment (EPA/630/P-03/001F). US Environmental Protection Agency, Washington, D.C., United States of America (Available at 〈https://www.epa.gov/sites/production/files/2013-09/documents/ cancerguidelinesfinal 3-25-05.pdf $\rangle$, Accessed 14 February 2017).

EFSA, 2008. Polycyclic aromatic hydrocarbons in food. EFSA J. 724, 1-114.

FAO, 2016. The State of World Fisheries and Aquaculture 2016. Food and agriculture organization of the United Nations, Rome.

Folch, J., et al., 1957. A simple method for the isolation and purification of total lipids from animal tissues. J. Biol. Chem. 226, 497-509.

Guinan, J., et al., 2001. Sources and geochemical constraints of polycyclic aromatic hydrocarbons (PAHs) in sediments and mussels of two Northern Irish Sea-loughs. Mar. Pollut. Bull. 42, 1073-1081.

Hamidi, E.N., et al., 2016. Polycyclic aromatic hydrocarbons (PAHs) and their bioaccessibility in meat: a tool for assessing human cancer risk. Asian Pac. J. Cancer Prev. $17,15-23$

Hong, W.-J., et al., 2016. Polycyclic aromatic hydrocarbons (PAHs) and alkylated PAHs in the coastal seawater, surface sediment and oyster from Dalian, Northeast China. Ecotoxicol. Environ. Saf. 128, 11-20.

Hornbuckle, K., Robertson, L., 2010. Polychlorinated biphenyls (PCBs): sources, exposures, toxicities. Environ. Sci. Technol. 44, 2749-2751.

IARC, 2002. Some traditional herbal medicines, some mycotoxins, naphthalene and styrene. Working Group on the Evaluation of Carcinogenic Risks to Humans, IARC Monographs on the Evaluation of Carcinogenic Risks to Humans. International Agency for Research on Cancer, vol. 82, pp. 1-556.

IARC, 2010. Some non-heterocyclic polycyclic aromatic hydrocarbons and some related exposures. Working Group on the Evaluation of Carcinogenic Risks to Humans, IARC Monographs on the Evaluation of Carcinogenic Risks to Humans. International Agency for Research on Cancer, vol. 92, pp. 1-853.

ISO, 2007. International Organization for Standardization - ISO/TS 17924:2007. Soil quality - assessment of human exposure from ingestion of soil and soil material guidance on the application and selection of physiologically based extraction methods for the estimation of the human bioaccessibility/bioavailability of metals in soil. Standards catalogue 13.080.30 - Biological properties of soils International Organization for Standardization, Geneva, Switzerland, 2007, pp. 16.

Kettrup, A., et al., 1999. Specimen banking as an environmental surveillance tool. Ann. Chim. 89, 489-498.

Kirso, U., Irha, N., 1998. Role of algae in fate of carcinogenic polycyclic aromatic hydrocarbons in the aquatic environment. Ecotoxicol. Environ. Saf. 41, 83-89.

Koch, I., et al., 2013. Variability of bioaccessibility results using seventeen different methods on a standard reference material, NIST 2710. J. Environ. Sci. Health Part AToxic/Hazard. Subst. Environ. Eng. 48, 641-655.

Ledesma, E., et al., 2014. Benzo (a) pyrene penetration on a smoked meat product during smoking time. Food Addit. Contam.: Part A 31, 1688-1698.

$\mathrm{Li}, \mathrm{W}$., et al., 2014. Atmospheric polycyclic aromatic hydrocarbons in rural and urban areas of northern China. Environ. Pollut. 192, 83-90.

López-Jiménez, F.J., et al., 2014. Determination of polycyclic aromatic hydrocarbons (PAH4) in food by vesicular supramolecular solvent-based microextraction and LC-fluorescence detection. Food Chem. 143, 341-347.

Maehre, H.K., et al., 2016. Heat treatment increases the protein bioaccessibility in the red seaweed dulse (Palmaria palmata), but not in the brown seaweed winged kelp (Alaria esculenta). J. Appl. Phycol. 28, 581-590.

Manita, D., et al., 2017. In vitro bioaccessibility of the marine biotoxins okadaic acid, dinophysistoxin-2 and their 7-O-acyl fatty acid ester derivatives in raw and steamed shellfish. Food Chem. Toxicol. 101, 121-127.

Martinez, E., et al., 2004. Simplified procedures for the analysis of polycyclic aromatic hydrocarbons in water, sediments and mussels. J. Chromatogr. A 1047, 181-188.

Mercogliano, R., et al., 2016. Occurrence and distribution of polycyclic aromatic hydrocarbons in mussels from the gulf of Naples, Tyrrhenian Sea, Italy. Mar. Pollut. Bull. 104, 386-390.

Miller, J.N., Miller, J.C., 2000. Statistics for Analytical Chemistry. Pearson Education Ltd., Harlow.

Mostafa, G.A., 2002. Monitoring of polycyclic aromatic hydrocarbons in seafoods from Lake Timsah. Int. J. Environ. Health Res. 12, 83-91.

Nasher, E., et al., 2016. Health risk assessment of polycyclic aromatic hydrocarbons through aquaculture fish consumption, Malaysia. Environ. Forensics 17, 97-106.

Naccari, C., et al., 2011. PAHs concentration in heat-treated milk samples. Food Res. Int. 44, 716-724.

Neđeral, S., et al., 2014. On-line DACC-HPLC analysis of polycyclic aromatic hydrocarbons in edible oils. Hrvat. časopis za Prehramben. Tehnol. Biotehnol. i Nutr. 8 74-81.

OEHHA, 2005. Office of Environmental Health Hazard Assessment - No Significant Risk Level (NSRL) for the Proposition 65 Carcinogen Naphthalene. Reproductive and Cancer Hazard Assessment Section. California Environmental Protection Agency, California, pp. 10

Olatunji, O.S., et al., 2015. Benzo [a] pyrene and Benzo [k] fluoranthene in some processed fish and fish products. Int. J. Environ. Res. Public Health 12, 940-951.

Olatunji, O.S., et al., 2014. Polycyclic aromatic hydrocarbons (PAHs) in edible oil: 
temperature effect on recovery from base hydrolysis product and health risk factor. Food Public Health 4, 23-30.

Oliveira, M., et al., 2017. Polycyclic aromatic hydrocarbons in primary school environments: levels and potential risks. Sci. Total Environ. 575, 1156-1167.

Ortega-Calvo, J.-J., et al., 2015. From bioavailability science to regulation of organic chemicals. Environ. Sci. Technol. 49, 10255-10264.

Palma-Fleming, H., Gutierrez, E., 2004. Polycyclic aromatic hydrocarbons in sediments and mussels of Corral Bay, south central Chile. J. Environ. Monit. 6, 229-233.

Perelló, G., et al., 2009. Concentrations of polybrominated diphenyl ethers, hexachlorobenzene and polycyclic aromatic hydrocarbons in various foodstuffs before and after cooking. Food Chem. Toxicol. 47, 709-715.

Ramalhosa, M.J., et al., 2012a. Lipid content of frozen fish: comparison of different extraction methods and variability during freezing storage. Food Chem. 131, 328-336.

Ramalhosa, M.J., et al., 2012b. Analysis of polycyclic aromatic hydrocarbons in fish: optimisation and validation of microwave-assisted extraction. Food Chem. 135, 234-242.

Ravindra, K., et al., 2008. Atmospheric polycyclic aromatic hydrocarbons: source attribution, emission factors and regulation. Atmos. Environ. 42, 2895-2921.

Ren, X., et al., 2014. Metabolic enzyme activities, metabolism-related genes expression and bioaccumulation in juvenile white shrimp Litopenaeus vannamei exposed to benzo(a)pyrene. Ecotoxicol. Environ. Saf. 104, 79-86.

Rodríguez-Navas, C., et al., 2017. In-vitro physiologically based extraction of solid materials: do we have reliable analytical methods for bioaccessibility studies of emerging organic contaminants? TrAC Trends Anal. Chem.

Saint-Denis, T., Goupy, J., 2004. Optimization of a nitrogen analyser based on the Dumas method. Anal. Chim. Acta 515, 191-198.

Schoeters, G., 2010. The REACH perspective: toward a new concept of toxicity testing. J. Toxicol. Environ. Health Part B 13, 232-241.

Silva, F.A.S., Azevedo, C.A.V., 2016. The Assistat software version 7.7 and its use in the analysis of experimental data. Afr. J. Agric. Res. 11, 3733-3740.

Singh, L., et al., 2016. Polycyclic aromatic hydrocarbons' formation and occurrence in processed food. Food Chem. 199, 768-781.

Soriano, J.A., et al., 2007. Spatial and temporal trends of polycyclic aromatic hydrocarbons in wild mussels from the Cantabrian coast (N Spain) after the Prestige oil spill. J. Environ. Monit. 9, 1018-1023.

Thea, A.E., et al., 2016. Polycyclic aromatic hydrocarbons (PAHs) in yerba maté (Ilex paraguariensis St. Hil) traditional infusions (mate and tereré). Food Control 60, 215-220.

Veiga, L., et al., 2014. Quantification of polycyclic aromatic hydrocarbons in toasted guaraná (Paullinia cupana) by high-performance liquid chromatography with a fluorescence detector. Food Chem. 152, 612-618.

Versantvoort, C.H., et al., 2005. Applicability of an in vitro digestion model in assessing the bioaccessibility of mycotoxins from food. Food Chem. Toxicol. 43, 31-40.

Wang, H.-S., et al., 2010. Oral bioaccessibility of polycyclic aromatic hydrocarbons (PAHs) through fish consumption, based on an in vitro digestion model. J. Agric. Food Chem. 58, 11517-11524.

Yu, Y.-X, et al., 2012. Polycyclic aromatic hydrocarbons in animal-based foods from Shanghai: bioaccessibility and dietary exposure. Food Addit. Contam.: Part A 29, 1465-1474. 